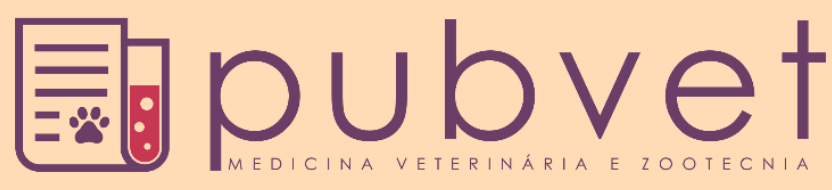

https://doi.org/10.31533/pubvet.v15n01a728.1-6

\title{
Registro de primeiro caso de leishmaniose visceral canina (alóctone) em Indaial - SC: Relato de caso
}

\author{
Kaio Gutieres Ebert ${ }^{1 \oplus}$, Leonardo Marchetti Motta ${ }^{1} \oplus$, Frank Hilton Rosa Júnior ${ }^{1} \oplus$, Edgar \\ Cardoso $^{2 \Phi}$, Keila Zaniboni Siqueira Batista ${ }^{2} \mathbb{9}$
}

${ }^{I}$ Acadêmico do curso de Medicina Veterinária da Universidade Regional de Blumenau - FURB.

${ }^{2}$ Docente do curso de medicina veterinária da Universidade Regional de Blumenau - FURB.

*Autor para correspondência, E-mail: keila_siqueira@furb.br

\begin{abstract}
Resumo. A leishmaniose visceral canina é uma doença de clima tropical, sendo comum em países das Américas. No Brasil, sua incidência vem crescendo devido o aumento de migrações de animais dentro do próprio país, o que pode elevar o índice de animais infectados pelo protozoário Leishmania chagasi. Este relato trata de uma cadela, de 2,5 anos de idade, oriunda do estado de São Paulo, que realizou uma viagem ao estado do Maranhão, cujos tutores vieram a fixar moradia em Indaial, SC. Logo após se estabelecerem nesta última cidade, o exemplar começou a apresentar sintomas característicos da leishmaniose visceral canina. Testes bioquímicos e diagnósticos sorológicos foram solicitados para a confirmação da suspeita e realização do tratamento.
\end{abstract}

Palavras-chave: Cães, Leishmania chagasi, Tripanosomatidae, zoonoses

\section{First case record of canine visceral leishmaniasis (allotone) in Indaial - SC: Case report}

\begin{abstract}
Canine visceral leishmaniasis is a tropical climate disease, commonly found in countries of the Americas. In Brazil, its incidence has been increasing due to the animal migrations within from the country itself, which have been rising the rate of animals infected by the protozoan Leishmania chagasi. This report describes a female dog, 2.5 years old, from São Paulo state, which made a trip to Maranhão state and whose tutors came to establish housing in Indaial, SC. Soon after settling in this city, the animal began to show characteristic symptoms of canine visceral leishmaniasis. Biochemical tests and serological diagnoses were requested to confirm the suspected and performed treatment.
\end{abstract}

Keywords: Dogs, Leishmania chagasi, Tripanosomatidae, zoonoses

\section{Introdução}

A leishmaniose visceral é uma doença zoonótica com caráter crônico, ocasionada pelo protozoário intracelular obrigatório Leishmania chagasi, que possui o cão como principal alvo dessa enfermidade. Devido sua ampla distribuição nas Américas, possui uma grande importância para a saúde pública e precisa ser notificada imediatamente em caso de suspeita (Alves, 2009). Sua transmissão ocorre através da picada da fêmea do mosquito do gênero Lutzomyia que inocula o parasito ao se alimentar do sangue do hospedeiro. No Brasil, o inseto transmissor é o artrópode da espécie Lutzomyia longipalpis, comumente conhecido como mosquito-palha devido sua coloração (BRASIL, 2019). Trata-se de um díptero da família Psycodidae, sendo o principal vetor da leishmaniose no mundo. Esse flebotomíneo de hábitos noturnos, apresenta dimensões menores que os mosquitos normais, e tem seu desenvolvimento em locais úmidos. São insetos que dificilmente ficam longe de seu abrigo, mas podem chegar a distancias de $1 \mathrm{~km}$, dependendo da disponibilidade de alimento. Deslocam-se em voos curtos e 
andam por superfícies, vivendo em locais como florestas, cavernas e ambientes antrópicos modificados (Ovallos, 2016).

No Brasil, essa doença tem uma alta incidência e atinge vários estados e cidades por todo o país. Tal fato causa uma grande preocupação pois caracteriza-se como uma doença com um alto potencial de letalidade, caso o diagnóstico seja tardio ou os sintomas não sejam tratados (Aguiar \& Rodrigues, 2017).

O parasito Leishmania causador dessa enfermidade foi descrito por Carlos Chagas e Cunha em 1993 (Silveira \& Corbett, 2010). Trata-se de um protozoário pertencente à família Trypanosomatidae, que possui dois estágios de desenvolvimento: promastigota e amastigota. A fêmea do vetor flebotomínio infectada possui as promastigotas em seu trato digestivo, que irão migrar via probóscide para serem inoculados durante o repasto. Uma vez inoculadas, na corrente sanguínea, as promastigotas serão fagocitadas pelos macrófagos. No interior dessas células, irão retrair seus flagelos, transformando-se em amastigotas, que se multiplicarão por divisão binária dentro do vacúolo parasitófago, até que a célula se rompa liberando os parasitas no tecido sanguíneo. Após esse ciclo ocorrido no hospedeiro, ao se alimentar do sangue dos animais e/ou humanos, o vetor ingere as amastigotas ou macrófagos infectados que, no estômago do mosquito, expressarão seus flagelos e retornarão ao estágio de promastigotas (Schimming \& Silva, 2012).

Além de ser um hospedeiro da doença, o cão pode exercer o papel de disseminador, uma vez que o animal infectado, ao ser picado por um mosquito transmissor, possivelmente transmitirá o protozoário para outros indivíduos. A transmissão ocorre quando o mosquito se alimenta do sangue de um cão infectado pela leishmania e passa a ficar contaminado. Devido à grande incidência de cães errantes nas cidades, a leishmaniose visceral está se tornando uma doença urbanizada e consequentemente, aumenta sua disseminação. A vinda de animais silvestres para as cidades, muitas vezes ligado a destruição de habitats, também influencia na epidemiologia da doença, devido esses animais também serem reservatórios da Leishmania chagasi (Sales et al., 2017).

A leishmaniose visceral canina (LVC) tem como testes diagnósticos o ensaio imunoenzimático (ELISA), o Dual Path Plataform (DPP), a reação de imunofluorescência indireta (RIFI) e análise parasitológica, sendo esse último de maior especificidade (Faria \& Andrade, 2012).

Um grande obstáculo no diagnóstico de animais infectados é o fato de que, na maioria das vezes, o canídeo pode ser assintomático, provavelmente passando despercebido e não sendo submetido a exames laboratoriais. Além disso, a existência de muitos cães errantes pelo país dificulta o levantamento epidemiológico mais abrangente de animais infectados por todo o território. Nesse sentido, o teste DPP pode ser realizado como triagem, na medida que tem como finalidade o diagnóstico rápido da doença, ficando pronto em apenas 15 minutos (Laurenti et al., 2014). Em caso de resultado positivo no teste imunocromatográfico, deve-se realizar um teste confirmatório, para exclusão de falsos positivos. O teste utilizado para uma verificação mais segura do estado do paciente é o teste de ELISA (Enzyme-Linked Immunosorbent Assay) por possuir uma maior confiabilidade (Faria \& Andrade, 2012).

$\mathrm{O}$ caso aqui apresentado relata uma cadela com 2,5 anos de idade que apresentava um quadro hemorrágico na região anal com inflamação na glândula perianal direita e fístulas na glândula esquerda. Diante disso, foi levantada a suspeita de leishmaniose visceral canina e o animal foi encaminhado para realização de exames e verificação da suspeita.

\section{Relato de caso}

Relata-se o caso de uma fêmea da espécie canina, da raça pastor alemão, cor branca, pesando 21,4 $\mathrm{kg}$, oriunda do estado de São Paulo que realizou uma viagem para o Maranhão, e seus tutores fixaram moradia na cidade de Indaial/SC. Este paciente foi atendido na Vira-Lata Clínica Veterinária e segundo seu tutor, já havia sido atendido em outra clínica veterinária da cidade por apresentar sangramento na região perianal, membros pélvicos e cauda com sangue. Lá teria sido administrado $500 \mathrm{mg}$ de ácido

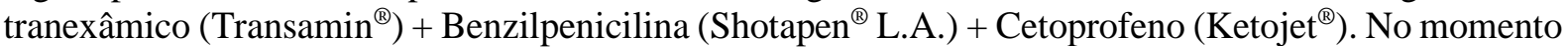
do exame clínico foi observado a hemorragia ativa na região perianal. Foi realizado sedação, tricotomia e limpeza de toda esta região, observou-se ainda sinusite paranasal esquerda fistulada que era a origem da hemorragia que foi controlada com compressão local. Ainda, observou-se sinusite paranasal purulenta do lado direito, esta última foi tratada com drenagem do seio. Após o tratamento local, foram 
indicadas as seguintes medicações: antibiótico a base de Enrofloxacina (Baytril ${ }^{\circledR} 150$ ) 7,5 mg/kg oral de 12/12 horas, Firocoxib (Previcox ${ }^{\circledR} 227 \mathrm{mg}$ ) $5 \mathrm{mg} / \mathrm{kg} / \mathrm{dia}$, e em virtude de tratar-se de uma época do ano muito quente indicou-se tratamento preventivo de míase com spray tópico a base de Cloridrato de Clorexidina (Organnact Prata ${ }^{\circledR}$ ) aplicado diariamente no local e Nitenpiram (Capstar ${ }^{\circledR}$ ) 57mg, 1 comp. a cada 48 horas nos primeiros 3 dias. Foi realizado acompanhamento clínico havendo boa cicatrização local.

Oito meses depois deste episódio, o animal foi atendido no mesmo serviço veterinário para vacinação anual. Porém, ao ser avaliado, o médico veterinário verificou as seguintes anormalidades: pele seca e pelagem opaca, crescimento exagerado das unhas (onicogrifose) secreção ao redor dos olhos que através do teste de Schirmer confirmou ceratoconjutivite seca, artralgia, abdômen abaulado e perda de peso. Além disso, o tutor relatou que o animal bebia muita água e urinava bastante (poliúria/polidipsia). Diante deste quadro supeitou-se de insuficiência renal crônica, mas alguns sinais eram sugestivos de leishmaniose visceral canina e, em virtude disto, foi solicitado exames complementares de imagem e de sangue. No exame de ultrassonografia, foi identificado hepatoesplenomegalia, além de um aumento discreto nas dimensões dos rins. Os resultados dos exames laboratoriais realizados estão apresentados na Tabela 1. Estes demonstraram aumento na ureia e creatinina, confirmando uma insuficiência renal crônica, bem como em seu eritrograma pode-se perceber anemia hipocrômica e microcítica, refletindo também em diminuição significativa nos níveis de albumina e aumento nos níveis de globulina. Seu leucograma e plaquetograma obtiveram valores dentro dos padrões de referência.

Tabela 1. Resultado dos exames bioquímicos e hematológicos do animal avaliado na cidade de Indaial-SC.

\begin{tabular}{lcc}
\hline Exame laboratorial & $*$ Resultados & $* *$ Valores de Referência \\
\hline Ureia & $241 \mathrm{mg} / \mathrm{dL}$ & $15-40 \mathrm{mg} / \mathrm{dL}$ \\
Creatinina & $2,29 \mathrm{mg} / \mathrm{dL}$ & $05-1,5 \mathrm{mg} / \mathrm{dL}$ \\
Fosfatase alcalina & $285 \mathrm{UI} / \mathrm{L}$ & $10-92 \mathrm{UI} / \mathrm{L}$ \\
GGT & $27,68 \mathrm{UI} / \mathrm{L}$ & $1-10 \mathrm{UI} / \mathrm{L}$ \\
Proteínas Totais & $8,8 \mathrm{mg} / \mathrm{dL}$ & $5,4-7,1 \mathrm{mg} / \mathrm{dL}$ \\
Albumina & $0,83 \mathrm{mg} / \mathrm{dL}$ & $2,6-3,3 \mathrm{mg} / \mathrm{dL}$ \\
Globulina & $7,97 \mathrm{mg} / \mathrm{dL}$ & $2,7-4,4 \mathrm{mg} / \mathrm{dL}$ \\
Rel. albumina/globulina & $0,1 \mathrm{mg} / \mathrm{dL}$ & $0,5-1,7 \mathrm{mg} / \mathrm{dL}$ \\
TGO & $39,98 \mathrm{UI} / \mathrm{L}$ & $10-88 \mathrm{UI} / \mathrm{L}$ \\
TGP & $12 \mathrm{UI} / \mathrm{L}$ & $10-88 \mathrm{UI} / \mathrm{L}$ \\
Eritrócitos (milhões) & $3.060 \mathrm{p} / \mathrm{mm}$ & $5.500-8.000 \mathrm{p} / \mathrm{mm}{ }^{3}$ \\
Hemoglobina & $6,0 \%$ & $12-18 \%$ \\
Volume Globular (VG) & $20,3 \%$ & $37-55 \%$ \\
Concentração de hemoglobina corpuscular & $29,5 \mathrm{pg} / \mathrm{mL}$ & $30-36 \mathrm{pg} / \mathrm{mL}$ \\
Proteína Plasmática Total & $9,8 \mathrm{mg} / \mathrm{dL}$ & $5,5-8,8 \mathrm{mg} / \mathrm{dL}$ \\
Volume corpuscular médio & $66,5 \mathrm{fL}$ & $60-77 \mathrm{fL}$ \\
Red Cell Distribution Width (Rdw) & $13,1 \%$ & $11-15 \%$ \\
Hemoglobina corpuscular média & $19.6 \mathrm{fL}$ & $19.5-24.5$ \\
\hline
\end{tabular}

*Exames realizados no laboratório da clínica veterinária Vira-Lata em Indaial/SC.

**R\&K Diagnóstico Veterinário.

Para a triagem da infecção por Leishmania, foi executado um teste rápido imunocromatográfico que apresentou resultado positivo, sugerindo a realização de testes mais precisos. Mais sangue foi coletado e o soro encaminhado para testes confirmatórios em laboratório de referência.

Enquanto aguardava-se os resultados dos exames encaminhados, foi realizado tratamento de suporte para insuficiência renal crônica, recebendo fluidoterapia com Ringer com Lactato, Doxiciclina $5 \mathrm{mg} / \mathrm{kg}$ BID, Domperidona $1 \mathrm{mg} / \mathrm{kg}$ BID, Prednisona $1 \mathrm{mg} / \mathrm{kg}$ BID e Alopurinol 10 mg/kg SID.

Após 6 dias de internamento observando-se melhora do estado geral, ganho de peso, retorno do apetite e disposição, foi concedido alta ao paciente, sendo recomendado a continuação do mesmo tratamento oral em domicílio incluído suplementação a sua dieta de $1500 \mathrm{mg}$ de ácido Eicosapentaenoico e ácido Docosahexaenoico (suplemento - Ograx ${ }^{\circledR}$ ). 
Os testes Reação de Imunofluorescência Indireta (IFI), para pesquisa de anticorpos anti-Leishmania e o ensaio imunoenzimático (ELISA), foram realizados pelo Laboratório de Tecnologia em Sanidade Animal (TECSA) em Belo Horizonte (MG). Em ambos os testes foi utilizado o soro do animal para detectar reações de anticorpos contra o possível parasito. No ELISA, obteve-se resultado reagente, assim como no RIFI, tendo como resultado a diluição 1/80, confirmando a suspeita de Leishmaniose Visceral. Neste momento foi comunicado a Vigilância Epidemiológica local que iniciou o acompanhamento do paciente.

Após o $11^{\circ}$ dia da consulta inicial foram solicitados novos exames de função renal, como ureia e creatinina (Tabela 2). Pôde-se observar um agravamento da função renal, diante do quadro renal, mas da melhora clínica, optou-se pela suspensão do tratamento com Doxiciclina, Domperidona, Prednisona e Alopurinol e iniciou-se o tratamento específico para leishmaniose visceral com Miltefosina $2 \mathrm{mg} / \mathrm{kg}$ SID (Milteforan ${ }^{\circledR}$ ) por 28 dias, solução oral; o animal apresentou melhora significativa já após o terceiro dia de tratamento específico.

Tabela 2. Resultados da segunda análise bioquímica do animal avaliado na cidade de Indaial-SC.

\begin{tabular}{lcc}
\hline Exames & $*$ Resultados & $* *$ Valores de Referência \\
\hline Ureia & $355 \mathrm{mg} / \mathrm{dL}$ & $15-40$ \\
Creatinina & $3,90 \mathrm{mg} / \mathrm{dL}$ & $0,5-1,5$ \\
\hline
\end{tabular}

*Exames realizados no laboratório da Clínica Veterinária Vira-Lata em Indaial-SC.

**R\&K Diagnóstico Veterinário.

Sessenta dias após a consulta inicial o animal retornou para procedimento de rotina (vacinação) e 90 dias após a consulta inicial continuava a ganhar peso e o tutor em virtude dos custos, e da melhora do quadro geral, não autorizou os exames da função renal. Neste período ganhou quatro quilos e clinicamente estava bem.

Após seis meses do diagnostico inicial voltou-se a entrar em contato por telefone com o tutor para saber do estado do paciente e este informou que havia novamente mudado de cidade e que o estado geral do paciente havia agravado nos últimos tempos e que havia optado pela eutanásia.

\section{Discussão}

A LVC é uma patologia que pode facilmente ser disseminada por intermédio de cães infectados que acabam sendo transportados para outros locais, difundindo a doença (CRMV/PR, 2015). Nesse relato, o animal avaliado era de procedência de outro estado (São Paulo) e, devido a mudança de domicílio, foi diagnosticado no município de Indaial, estado de Santa Catarina. Por ser uma doença de alto índice de transmissibilidade e, no caso dos animais, o tratamento ser intenso e sem garantia de melhoras, o indicado para pacientes positivos para LVC é à eutanásia (CRMV/PR, 2015). Apesar dessa indicação, o proprietário optou por realizar o tratamento.

Em Santa Catarina, o índice de LVC cresceu devido a um surto que, segundo a Prefeitura Municipal de Florianópolis, desde 2012 vem ocorrendo na cidade. A capital catarinense possui diversos animais positivos para leishmaniose, tendo como principal foco a região da Lagoa da Conceição. A principal possibilidade desse aglomerado de casos nessa região é o fato de o mosquito transmissor utilizar locais mais úmidos para sua proliferação, característica relacionada a esse flebotomíneo (Steindel et al., 2013). Segundo dados cedidos pela Diretoria de Vigilância Epidemiológica (DIVE, 2000), na capital catarinense foram analisados 18.520 cães, registrando 627 casos autóctones de LVC entre o período de 2010 até maio de 2020, ocorrendo um aumento significativo no número de casos a partir do ano de 2013. Ainda em Florianópolis, também foram registrados 91 casos importados a partir do ano de 2011.

As demais cidades do estado não têm registro de dados autóctones, apenas de casos importados. Na região de Blumenau foram notificados 42 casos importados de leishmaniose visceral canina, no período de 2012 a 2020, onde 10 animais foram positivados para a doença (DIVE, 2000).

A paciente apresentava hepatomegalia que, segundo Vieira Neto et al. (2011), pode estar relacionada ao fato de ser uma doença de caráter crônico, o que acaba gerando reação inflamatória granulomatosa após visceralização do parasito. Essa anormalidade no fígado do animal é a possível causa das alterações 
nos resultados da enzima gamaglutamiltransferase (GGT) e fosfatase alcalina (FA) que pode ser uma indicação de colestase (Castro et al., 2012). Além disso, há inversão da relação albumina/globulina nos testes do animal que, de acordo com os mesmos autores, pode ser explicada pela síntese aumentada de anticorpos anti-Leishmania, que se caracterizam como $\beta$ e $\gamma$ globulinas, o que possivelmente causou o aumento de proteínas totais e, consequentemente, a diminuição dos níveis de albumina.

Os exames bioquímicos de função renal apresentavam uma elevação significativa dos níveis de ureia e creatinina, no qual pode-se indicar uma possível doença renal crônica (DRC) (Souza et al., 2012). A literatura ressalta que uma das características marcantes de cães sintomáticos é a insuficiência renal crônica, sendo a principal causa de morte em casos de LVC (Vieira Neto et al., 2011).

No exame de ultrassom da cadela também foi possível observar uma esplenomegalia, o que pode estar relacionado com o sequestro esplênico e/ou diminuição da eritropoiese causada pelos protozoários. Segundo Bruniera (2007), por proliferarem-se no tecido sanguíneo, podem causar essas alterações, gerando anemia, o que foi perceptível pelos índices do eritrograma da paciente estarem abaixo dos valores de referência.

Os testes comumente utilizados para o imunodiagnóstico da leishmaniose visceral canina são o teste rápido imunocromatográfico (DPP) e, como confirmatório, o ELISA e o RIFI (Souza et al., 2012). No cão deste relato foi realizado o DPP, com resultado positivo, seguido de ambos os confirmatórios, também com resultados positivos para leishmaniose. Esses exames tiveram grande importância para a confirmação da suspeita clínica.

\section{Conclusão}

A leishmaniose visceral canina é uma patologia de suma importância na saúde pública, devido sua fácil transmissibilidade e pelo fato de os humanos estarem constantemente em contato com os cães, estando expostos a doença. É importante que sejam feitos os exames bioquímicos e testes de diagnósticos confirmatórios para uma análise mais precisa do quadro clínico do animal, além de alertar ao proprietário de seu caráter zoonótico e os perigos da fácil transmissibilidade dessa enfermidade.

\section{Referências}

Aguiar, P. F., \& Rodrigues, R. K. (2017). Leishmaniose visceral no Brasil: artigo de revisão. Unimontes Científica, 19(1), 191-204.

Alves, W. A. (2009). Leishmaniose visceral americana: situação atual no Brasil. BEPA. Boletim Epidemiológico Paulista (Online), 6(71), 25-29.

BRASIL. (2019). Leishmaniose Visceral: o que é, causas, sintomas, tratamento, diagnóstico e prevenção. Ministério Da Saúde. http://portalms.saude.gov.br/saude-de-a-z/leishmaniose-visceral

Bruniera, P. (2007). Crise de seqüestro esplênico na doença falciforme. Revista Brasileira de Hematologia e Hemoterapia, 29(3). https://doi.org/10.1590/S1516-84842007000300012

Castro, I. P., Sousa, M. V. C., Magalhães, G. M., Mundim, A. V., Noleto, P. G., Paula, M. B. C., Neto, A. de A. P., \& Medeiros, A. A. (2012). Perfil hepático e protéico em cães com leishmaniose visceral. Bioscience Journal, 28(5 SE-Agricultural Sciences). http://www.seer.ufu.br/index.php/biosciencejournal/article/view/12120

DIVE - Diretoria de Vigilância Epidemiológica. (2000). [mensagem pessoal]. Mensagem recebida por:<dvrh@saude.sc.gov.br>. Em: 1 jun 2020.

Faria, A. R., \& Andrade, H. M. (2012). Diagnóstico da Leishmaniose Visceral Canina: grandes avanços tecnológicos e baixa aplicação prática. Revista Pan-Amazônica de Saúde, 3(2), 47-57. https://doi.org/10.5123/S2176-62232012000200007

Laurenti, M. D., Leandro, M. V. S., Tomokane, T. Y., Lucca, H. R. L., Aschar, M., Souza, C. S. F., Silva, R. M., Marcondes, M., \& Matta, V. L. R. (2014). Comparative evaluation of the DPP® CVL rapid test for canine serodiagnosis in area of visceral leishmaniasis. Veterinary Parasitology, 205(34), 444-450. https://doi.org/10.1016/j.vetpar.2014.09.002

Ovallos, F. G. (2016). Leishmaniose visceral americana: avaliação dos parâmetros da capacidade vetorial de Lutzomyia longipalpis em área urbana do muncípio de Panorama, São Paulo, Brasil [Universidade de São Paulo]. https://doi.org/10.11606/T.6.2016.tde-17032016-133512 
Sales, D. P., Chaves, D. P., Martins, N. S., \& Silva, M. I. S. (2017). Aspectos Epidemiológicos da Leishmaniose Visceral Canina e Humana no Estado do Maranhão, Brasil (2009-2012). Revista Brasileira de Ciência Veterinária, 24(3), 144-150. https://doi.org/10.4322/rbcv.2017.028

Schimming, B. C., \& Silva, J. R. C. P. (2012). Leishmaniose visceral canina - Revisão de literatura. Revista Científica Eletrônica de Medicina Veterinária, 10(18), 1-5. http://hdl.handle.net/11449/140317

Silveira, F. T., \& Corbett, C. E. P. (2010). Leishmania chagasi Cunha \& Chagas, 1937: indigenous or introduced? A brief review. Revista Pan-Amazônica de Saúde, 1(2). https://doi.org/10.5123/S217662232010000200018

Souza, M., Nunes, R. F., Viana, T., Marinho, M. M., Moreira, P. V. S., \& Pereira, W. (2012). Leishmaniose Visceral Humana: do Diagnóstico ao Tratamento. Revista de Ciências Da Saúde Nova Esperança, 10(2 SE-Artigo Original). https://doi.org/10.17695/revnevol10n2p62 - 70

Steindel, M., Menin, Á., Evangelista, T., Stoco, P. H., Marlow, M. A., Fleith, R. C., Pilati, C., \& Grisard, E. C. (2013). Outbreak of autochthonous canine visceral leishmaniasis in Santa Catarina, Brazil. Pesquisa Veterinária Brasileira, 33(4), 490-496. https://doi.org/10.1590/S0100-736X2013000400013

Vieira Neto, F. A., Sousa, A. K. S., Marques, M. V., Arruda, D. S., \& Silva, L. A. (2011). Avaliação de parâmetros bioquímicos em cães infectados por Leishmania chagasi. Revista de Ciências Da Saúde, $13(2)$.

\section{Histórico do artigo:}

Recebido: 29 de julho, 2020.

Aprovado: 31 de agosto, 2020

Disponível online: 17 de novembro, 2020
Licenciamento: Este artigo é publicado na modalidade Acesso Aberto sob a licença Creative Commons Atribuição 4.0 (CC-BY 4.0), a qual permite uso irrestrito, distribuição, reprodução em qualquer meio, desde que o autor e a fonte sejam devidamente creditados. 